\title{
Carboplatin/Cetuximab Regimen
}

National Cancer Institute

\section{Source}

National Cancer Institute. Carboplatin/Cetuximab Regimen. NCI Thesaurus. Code C150687.

A chemoimmunotherapy regimen consisting of carboplatin and cetuximab that can be used for the treatment of head and neck cancer. 